\title{
FONTES DE INFORMAÇÃO PARA GERAÇÃO DA INTELIGÊNCIA COMPETITIVA NAS ORGANIZAÇõES: uma revisão ampliada de literatura
}

\section{SOURCES OF INFORMATION FOR GENERATING COMPETITIVE INTELLIGENCE IN ORGANIZATIONS: an extended literature review}

\author{
Renata Costa Ferreira ${ }^{1}$ \\ Vaniélli Maria César Jardim² \\ Fabricio Ziviani ${ }^{3}$
}

\footnotetext{
${ }^{1}$ Mestranda em Sistemas de Informação e Gestão do Conhecimento.
}

E-mail: informacaoempauta@gmail.com

${ }^{2}$ Mestranda em Sistemas de Informação e Gestão do Conhecimento.

E-mail: informacaoempauta@gmail.com

${ }^{3}$ Doutor em Ciência da Informação pela Escola de Ciência da Informação da Universidade Federal de Minas Gerais.

E-mail: informacaoempauta@gmail.com

\section{ACESSO ABERTO}

Copyright: Esta obra está licenciada com uma Licença Creative Commons Atribuição 4.0 Internacional. $(\mathrm{cc}) \mathrm{EY}$

Conflito de interesses: Os autores declaram que não há conflito de interesses.

\section{Financiamento: Não há.}

Declaração de Disponibilidade dos dados: Todos os dados relevantes estão disponíveis neste artigo.

Recebido em: 23/08/2018.

Aceito em: 16/10/2018.

Revisado em: 02/12/2018.

\section{Como citar este artigo:}

FERREIRA, Renata Costa; JARDIM, Vaniélli Maria César; ZIVIANI, Fabricio. Fontes de informação para geração da inteligência competitiva nas organizações: uma revisão ampliada de literatura. Informação em Pauta, Fortaleza, v. 3, n. 2, p. 50-73, jul./dez. 2018. DOI: https://doi.org/10.32810/25253468.ip.v3i2.2018.33475.50-72.

\section{RESUMO}

A gestão do conhecimento vem sendo trabalhada nas últimas décadas associada à tecnologia e inovação e seu impacto positivo nas organizações. Este estudo aborda as fontes de informação sob a perspectiva da gestão da informação para geração de inteligência competitiva. A metodologia adotada é uma revisão ampliada de literatura que analisa os artigos publicados na área acadêmica nos anos de 2007 a 2018 que abordam o tema Fontes de Informação, Competitividade e Inteligência Competitiva. Os fatores de inclusão são revistas A1, A2 e B1 avaliadas no Qualis Capes pela área de Comunicação e Informação. 0 estudo objetiva analisar as publicações em periódicos sobre o tema fontes de informação para geração de inteligência competitiva nas organizações. A amostra totalizou 23 artigos coletados na Base Sci Verse SCOPUS que se enquadraram nos critérios de inclusão deste estudo. Para a confecção dos mapas e análise de densidade foi utilizado o software Vosviewer. Os artigos examinados na amostra demonstram que as pesquisas sobre informação, fonte de informação e inteligência competitiva convergem para o paradigma econômico e tecnológico e que as fontes de informação são ferramentas importantes para que a gestão da informação possa emergir como mecanismo estratégico essencial ao desempenho empresarial. 
Palavras-chave: Gestão da informação. Fontes de informação. Uso da informação. Competitividade. Inteligência competitiva.

\begin{abstract}
Knowledge management has been worked in the last decades associated with technology and innovation and its positive impact on organizations. This study approaches the sources of information from the perspective of information management to generate competitive intelligence. The methodology adopted is an extended literature review that analyzes the articles published in the academic area in the years 2007 to 2018 that deal with the theme of Information Sources, Competitiveness and Competitive Intelligence. The inclusion factors are reviewed A1, A2 and B1 evaluated in the Qualis Capes by the area of Communication
\end{abstract}

and Information. The study aims to analyze the publications in periodicals about the theme of information sources for generating competitive intelligence in organizations. The sample consisted of 23 articles collected at the Sci Verse SCOPUS Base that were included in the inclusion criteria of this study. The Vosviewer software was used for mapping and density analysis. The articles examined in the sample show that research on information, information sources and competitive intelligence converge to the economic and technological paradigm and that information sources are important tools for information management to emerge as a strategic mechanism essential to business performance.

Keywords: Information management. Information sources. Use of information. Competitiveness. Competitive Intelligence.

\section{INTRODUÇÃO}

0 aumento da concorrência em vários setores mercadológicos, além do surgimento de novas tecnologias têm desafiado empresas e negócios. As mudanças de paradigma do mercado vem dando espaço a inovação e criando estruturas de baixo custo e alto valor agregado. Para lidar com esses desafios e otimizar sua participação no mercado, as organizações precisam encontrar formas de desenvolver e consolidar vantagens competitivas frente aos concorrentes. Assim, destaca-se a importância da divulgação de informações nas organizações para tomadas de decisões. Neste artigo, a disseminação da informação dentro das premissas da gestão do conhecimento é abordada como uma fonte de inteligência competitiva.

A expansão da gestão da informação para gestão do conhecimento faz com que os sistemas sejam requisitados para processar as informações informais e os produtos das atividades intelectuais. Cria-se uma necessidade de abrangência das informações externas e internas coletadas e disseminadas como uma forma de transformar informações em conhecimento estratégico. As organizações precisam entender a importância da informação e do conhecimento como recurso a ser trabalhado pelos gestores, a partir da análise das fontes de informação.

Segundo Rodrigues e Blattmann (2014, p. 15), a "utilização de fontes de informação é priorizada de acordo com as três premissas defendidas por Choo (2006): 
uma organização processa a informação para dar sentido a seu ambiente, para criar novos conhecimentos e para tomar decisões". Embora a obtenção dos conhecimentos seja captada de fontes externas e internas, cada empresa tem sua forma de aplicar essa informação em função da complexidade organizacional e dos diferentes fluxos internos de processos. Neste contexto, a premissa central desta pesquisa é a fonte de informação sob a perspectiva da gestão do conhecimento para geração de inteligência competitiva.

Este estudo objetiva analisar as publicações em periódicos sobre o assunto fontes de informação para geração de inteligência competitiva nas organizações. Tal objetivo é justificado pela necessidade de se conhecer o comportamento da literatura acerca do tema de interesse. A metodologia adotada é a revisão ampliada de literatura que analisa os artigos publicados na área acadêmica nos anos de 2007 a 2018 que abordam o tema. Para isso, foi aplicado o software VOSviewer e utilizada a base Sci Verse SCOPUS para levantamento dos trabalhos publicados com as palavras-chave inteligência competitiva, competitividade, fonte de informação e gestão do conhecimento.

0 artigo em questão está estruturado da seguinte forma: primeiramente, apresenta alguns estudos sobre a gestão da informação, fontes de informação e inteligência competitiva, posteriormente apresenta-se o método adotado, para depois expor os resultados e a discussão e por fim as considerações finais.

\section{REFERENCIAL TEÓRICO}

\subsection{A informação nas organizações}

A mudança de paradigma da sociedade nos últimos anos e os avanços consideráveis na era da indústria e prestação de serviços tiveram um impacto direto na forma como as empresas passaram a gerir seu conhecimento e aplicá-lo internamente. A transição de uma sociedade cuja base principal das atividades econômicas era a indústria e o transporte para outra baseada na informação e no conhecimento foi a responsável por uma maior ênfase na gestão estratégica da informação nos últimos anos.

Nesse novo contexto econômico e tecnológico, a gestão da informação revela-se como um importante método estratégico ao desempenho organizacional, uma vez que procura compreender as necessidades da informação e intensifica os recursos utilizados, 
orientando-os a aprender e adequar-se às demandas impostas pelo ambiente. Costa (2003), Rodrigues e Blattmann (2014, p. 7) afirmam que "a informação é concebida como matéria-prima para gerar o conhecimento. A literatura sobre gestão do conhecimento coloca o conhecimento tácito e as informações de caráter informacional como vitais para a sobrevivência em mercados cada vez mais competitivos".

Por outro lado, Davenport (2000, p. 173) e Rodrigues e Blattmann (2014, p. 7) definem o gerenciamento da informação como processos, isto é, "um conjunto estruturado de atividades que incluem o modo como as empresas obtêm, distribuem e usam a informação e o conhecimento". A informação é percebida como elemento para inovação e competitividade e utilizada na promoção da gestão da informação para criar estratégias, consolidando a importância do homem como recurso essencial do processo.

Taylor (1991 apud BRUM; BARBOSA, 2009) propõe oito categorias baseadas na relevância que os seres dão à informação. São elas:

[...] o esclarecimento, a compreensão do problema, a parte instrumental, a questão factual, a confirmação, a projeção de um acontecimento, a motivação e as questões pessoais e políticas. Taylor (1991) aponta que os trabalhos de Dervin e Nilan (1986) e colegas foram importantes referências para esta categorização. (BRUM; BARBOSA, 2009, p. 56).

Segundo Dervin e Nilan (1986 apud BRUM; BARBOSA, 2009, p. 57),

[...] no esclarecimento, a informação é usada para desenvolver um contexto adequado ou para criar sentido a uma situação. A informação é trabalhada para responder questões sobre a organização. Para o entendimento do problema, a informação é usada em um caminho mais específico do que na categoria anterior. Ela é usada para desenvolver uma melhor compreensão de um problema particular. Dervin chama de capacidade de decidir, preparar e planejar. Na parte instrumental descobre-se o que fazer e como fazer alguma coisa. As instruções são uma forma comum de informação instrumental. Para Dervin, é o desenvolvimento de habilidades para ler e interpretar as instruções. $\mathrm{Na}$ questão factual a informação é usada para determinar os fatos de um fenômeno ou evento, para descrever a realidade. 0 uso da informação factual depende de dois fatores: a) a qualidade e atualidade da informação (o quão ela representa fielmente a realidade); e, relacionada com o fator acima, b) a percepção da qualidade por parte dos usuários.

Os autores ainda discorrem sobre as demais categorias. Sendo elas:

A necessidade de confirmar um trecho ou pedaço da informação é um tipo de uso chamado por Taylor de confirmação. Ela envolve a busca por uma segunda opinião. Se essa nova opinião não se confirmar, então o indivíduo pode reformular o problema para tentar reinterpretar a informação ou escolher outra fonte para confiar. É uma atitude comumente verificada em gerentes. 0 uso projetivo da informação serve para verificar o que irá acontecer no futuro. É utilizada tipicamente para estimativas, probabilidades e previsões, não para 
situações pessoais, mas em termos mais gerais e amplos. A categoria motivacional usa a informação para manter as pessoas em uma atividade contínua, através do envolvimento interpessoal em torno de um objetivo. E por último, a informação usada para fins pessoais e políticos melhora o envolvimento e o desenvolvimento de relacionamentos e aumenta seu status e sua reputação diante de situações diárias e o do trabalho. (TAYLOR, 1991 apud BRUM; BARBOSA, 2009, p. 57).

A dificuldade de interpretação dos cenários e a pouca relevância informacional podem criar a incerteza ambiental. Na visão de Duncan (1972), a incerteza decorre da complexidade e do dinamismo do ambiente no qual a organização está inserida. Para evitar esse tipo de problema, as empresas devem preocupar-se em aproveitar as informações do ambiente, estudá-las e aproveitá-las utilizando a percepção resultante para gerar conhecimento e resultados, aclarando as possibilidades e reduzindo as incertezas mercadológicas. Para Campos (2007 apud FEITOSA; CALDAS; CÂNDIDO, 2011), "profissionais que conhecem o ambiente no qual desempenham suas atividades expressam menores índices de incerteza."

\subsection{Fontes de informação: conceito e classificação}

As empresas e o mercado na era informacional produzem um grande volume de dados que podem ser filtrados e organizados de forma a produzir significado. Dessa maneira, os mesmos são convertidos em informação. A forma de obtenção desses dados posteriormente transformados é chamada de fonte de informação. "As fontes de informação ou documentos podem abranger manuscritos e publicações impressas, além de objetos, como amostras minerais, obras de arte ou peças museológicas, podendo ser divididas em três categorias: documentos primários, documentos secundários e documentos terciários". (CUNHA, 2001; RODRIGUES; BLATTMANN, 2014, p. 9).

O gerenciamento das informações nas empresas passa por um fluxo composto por etapas contínuas e organizadas sistematicamente, com indivíduos atuantes e incubidos dessa gestão, além da utilização das informações obtidas através das fontes. É necessário conhecer as demandas de uso e os usuários da informação para melhor mapeamento das fontes. Choo $(1994,2006)$ e Rodrigues e Blattmann (2014, p. 9), classificam as fontes de informação em quatro categorias: "externas e pessoais, externas e impessoais, internas e pessoais, e internas e impessoais".

Ribeiro (2009), Rodrigues e Blattmann (2014), as agruparam conforme abaixo: 
Fontes pessoais externas são compostas por pessoas ou informações obtidas de fora da organização tais como colegas de outras empresas, clientes, concorrentes, consultores, corretores, parceiros, feiras e palestras.

Fontes pessoais internas são pessoas ou informações de dentro da organização tais como empregados, colegas de trabalho, superiores hierárquicos, sócios (interação presencial ou telefônica).

Fontes pessoais eletrônicas são compostas por informações em bases de pesquisa da web tais como e-mail (pessoal ou da empresa), fóruns, grupos de discussão online, Messenger, Skype e similares.

Fontes impessoais externas são documentos produzidos fora da empresa, como revistas, jornais, livros, relatórios, periódicos técnicos, regulamentos, etc.

Fontes impessoais internas são documentos produzidos dentro da empresa, como relatórios, estudos, memorandos, arquivos em papel e anotações de trabalho.

Fontes impessoais eletrônicas são documentos eletrônicos em geral, intranet, base de dados eletrônica da empresa, site da empresa, bancos de dados, sites de notícia, etc.

A maioria das empresas utiliza as fontes de informação classificadas conforme os seguintes tipos: competidores, governo, fornecedores, clientes, associações profissionais, associações de classe, empregados, consultores e imprensa especializada. Essas fontes podem ser técnicas, informações para negócios e informações científicas. Sutton (1988) e Pereira (2016) identificaram quatro grupos de fontes de informação: fontes internas, contatos diretos com o setor de negócios, informações publicadas e outras fontes. Segundo os autores, essas fontes foram destacadas como importantes pelos administradores.

Algumas fontes de informação são importantes no trabalho de monitoramento da concorrência. São elas: artigos de jornais, revistas, publicações especializadas, relatórios de analistas de investimentos, estudos publicados, planos de expansão, anúncios dirigidos, anúncios de oferta de emprego, calendários de eventos, exposições e feiras, pesquisas especiais, clippings de notícias, literatura sobre produtos, arquivos públicos e contatos pessoais.

Para Choo (1998) e Pereira (2016) as fontes de informação podem ser categorizadas em três níveis diferentes: fontes pessoais (subdivididas em fontes internas ou externas); fontes documentais (subdivididas em fontes publicáveis ou 
documentos internos da organização); e fontes eletrônicas (formadas pelas bases de dados online, CD-ROMs e Internet). Os autores ainda destacam a importância da Internet no processo de disseminação da informação dentro da categoria fontes eletrônicas Ressaltam também a utilização do e-mail, grupos e chats de discussão, grupos de notícias, sites e portais.

Com o grande aumento do acesso à internet, os usuários da informação estão utilizando-a como uma das principais fontes para adquirir informação. Para Tomaél et al (2001, p. 3) ela é o "resultado da convergência das tecnologias da computação e da comunicação; a internet representa uma verdadeira revolução nos métodos de geração, armazenagem, processamento e transmissão da informação". (BRUM; BARBOSA, 2009, p. 60).

Os autores ainda afirmam que:

Não se pode negar que a internet ocupa um espaço importante nos processos informacionais e, atualmente, é uma fator determinante no comportamento informacional do indivíduo em termos de necessidade, busca e uso da informação. Situação comprovada por estudos como o de Choo, Detlor e Turnbull (1999), visto que eles pesquisam os comportamentos de busca baseados na web por trinta e quatro tipos diferentes de usuários, de sete empresas e de três setores diferentes. (BRUME E BARBOSA, 2009, p. 61).

Cendón (2002) e Pereira (2016), por outro lado, abordam o conceito de "informação para negócios". Segundo os autores trata-se de um conjunto de informações usadas por administradores para auxiliar na tomada de decisão. Além de serem consideradas como subconjunto da informação tecnológica contribuindo para o desenvolvimento industrial, técnico, econômico, mercadológico, gerencial e social. Os autores também chamaram a atenção para a tendência de evolução das redes de comunicação em que a informação em formato eletrônico ganha maior importância.

As fontes de informação podem ser utilizadas pelas organizações em três principais fluxos informacionais: fluxo de informações criadas pela empresa para seu próprio uso; informações produzidas pela empresa com orientação para fora e informações coletadas externamente e orientadas para dentro. A classificação dos tipos de fontes disponíveis auxiliam as empresas na escolha daquelas que melhor se adequem ao seu contexto mercadológico e as suas demandas organizacionais. 


\subsection{Importância e utilização das fontes de informação}

As empresas farão as escolhas das melhores fontes e dentro delas o levantamento das informações necessárias a suas demandas de negócio. Os usuários envolvidos no processo serão parte fundamental dentro dessas escolhas. A informação separada do usuário não traz valor, ou seja, a utilização de processos que envolvam o uso da informação devem estar alinhadas às necessidades específicas dos usuários.

O uso adequado da informação é dependente da qualidade e da relevância das fontes de informação identificadas pelo usuários da informação. 0 uso da informação "encontrada depende também de como o indivíduo avalia a relevância cognitiva e emocional da informação recebida e atributos objetivos capazes de determinar a pertinência da informação a uma determinada situação problemática." (CHOO, 2003 apud BRUM; BARBOSA, 2009, p. 57).

Choo (2003), Pereira e Barbosa (2007) ponderam que as empresas utilizam a informação em três níveis classificados como arenas estratégicas. Na primeira delas a informação é utilizada para dar significado aos processos e ações da empresa, além da sua introdução em novos mercados, na segunda, a informação é utilizada para a criação de novos conhecimentos além de unificar experiências entre os membros da empresa tornando o ambiente propício ao aprendizado e a inovação e na terceira, a organização processa e analisa a informação que é utilizada como recurso na escolha de estratégias para a tomada de decisão. As três arenas apesar de serem considerados processos independentes são, na prática, interligados, e a análise dos mesmos é denominada pelos autores em visão holística do uso da informação.

A aquisição e o propósito de utilização da informação são fatores relevantes para transformações sociais e econômicas. Os autores defendem a integração da gestão da informação e do conhecimento nos ambientes empresariais, contribuindo, assim, para a competitividade das organizações. Em um contexto empresarial complexo e mutável, a informação é considerada um recurso essencial na promoção do diferencial competitivo, uma vez que concede aos gestores, elementos para a interpretação de estímulos e indícios do ambiente externo. Esses indícios, quando interpretados de maneira correta, criam um entendimento que ao ser compartilhado com os membros principais da organização gera o conhecimento necessário à formulação de estratégias.

Gerenciar uma organização orientada para o conhecimento significa utilizar os elementos e recursos disponíveis para aumento da qualidade e eficiência através do 
crescimento das capacidades essenciais baseadas nas informações disponíveis convertendo-as em vantagens competitivas que chegarão a ser quantificáveis através do bom resultado de suas atividades.

\subsection{Inteligência competitiva e informação}

O crescimento da concorrência e o aumento da competitividade tem acirrado os mercados e obrigado empresas a desenvolverem estratégias cada vez mais consistentes para criarem posições consolidadas e oferecer mais valor que a concorrência. 0 desenvolvimento dessas estratégias muitas das vezes está ligado ao conhecimento e monitoramento desses mercados obtido através de uma ampla análise de informações. Nesse contexto, as informações formam a base para a Inteligência Competitiva.

A forma sustentável de crescimento de uma organização incide sobre o conhecimento do mercado de atuação, dos concorrentes, dos clientes e dos consumidores. Assim, a informação, base do processo de Inteligência Competitiva, pode criar significado e construir esse conhecimento, auxiliando as organizações no planejamento estratégico e no processo de tomada de decisão. (QUEYRAS E QUONIAM, 2006; MARQUES; VIDIGAL, 2018, p. 4).

A inteligência competitiva pode ser conceituada de várias formas como citam alguns autores:

Fuld (1995) define IC como informação analisada, que ajuda na tomada de decisão tática e estratégica. Para Miler (2002), o processo de inteligência está baseado na compreensão de que os gestores necessitam estar informados sobre diversas questões relacionadas ao negócio, de maneira formal e sistemática, gerando informações relacionadas a acontecimentos futuros que proporcionam vantagens sobre os concorrentes. A inteligência competitiva para Taparanoff (2006, p. 26) é definida como "um processo de aprendizado motivado pela competição, fundado sobre a informação, permitindo esta última a otimização da estratégia corporativa em curto e em longo prazo". (MARQUES; VIDIGAL, 2018, p. 4).

Processo institucional composto por planejamento, coleta, análise e disseminação de informações transformadas em inteligência, que amparam os gestores, com eficiência e eficácia, em seus processos decisórios. (MARQUES; VIDIGAL, 2018, p. 4). Para que o processo de inteligência competitiva alcance o resultado desejado é fundamental desenvolver uma cultura interna que favoreça o compartilhamento das informações entre todos os membros da organização, além de promover o efetivo apoio da alta administração. (BERNHARDT, 2003; FLEISHER; BENSOUSSAN, 2007; FULD, 1995; 
MARQUES; VIDIGAL, 2018; MILLER, 2002; MURPHY, 2005; ROTHBERG; ERICKSON, 2005; WEST, 2001).

A IC funciona como um importante recurso estratégico uma vez que possibilita a antecipação de acontecimentos futuros baseados em informações auxiliando os gestores na tomada de decisão e criando vantagem em relação a concorrência (MARQUES; VIDIGAL, 2018).

Através dos dados e informações relevantes sobre determinado contexto competitivo, os agentes envolvidos no processo de IC fazem o direcionamento dos esforços para a transformação dos mesmos em recursos da inteligência competitiva que serão acionados pelos gestores, sendo eles, exposições, apresentações ou mesmo relatórios de alta valor para a tomada de decisão (OLIVEIRA; SADE, 2016).

Existem vários modelos de inteligência competitiva, mas que a maioria é definida como Ciclo de Inteligência Competitiva, composta por cinco fases - identificação das necessidades; planejamento e direção; coleta; análise; e disseminação -, afirmando que nenhuma delas se sustenta sozinha, pois todas são necessárias e agregam valor umas às outras. (PRESCOTT, 2002; MARQUES; VIDIGAL, 2018)

A fase de identificação consiste no levantamento das necessidades das pessoas estratégicas e dos usuários; o planejamento compreende a sondagem das necessidades e identificação dos implicados no processo, assim como as respostas relacionadas aos tipos de busca de dados e análises e também os recursos. Na etapa de coleta serão definidas as fontes de informação que serão aplicadas e para a etapa de análise é fundamental que os processos sejam realizados de forma proativa e inovadora, através de investigação e conferência, mediante sondagens e semelhanças para aumentar o valor agregado. E por fim, a etapa de implantação e avaliação transforma as informações em produtos de inteligência e disponibiliza os mesmos ao público interessado (MARQUES; VIDIGAL, 2018).

\section{MATERIAIS E MÉTODOS}

A metodologia adotada foi a revisão ampliada de literatura sob o critério artigos publicados na área acadêmica entre os anos de 2007 a 2018 que abordam os temas Fontes de Informação, Competitividade e Inteligência Competitiva. A revisão sistemática origina os dados que serão posteriormente tratados através de uma análise 
bibliométrica ou bibliometria. Estes podem ser entendidos como unidades de medida para o tratamento dos dados da revisão sistemática (MEDEIROS; VIEIRA; BRAVIANO; GONÇALVES, 2015, p. 98).

Uma problemática comum, muitas vezes é encontrar publicações pertinentes e utilizar critérios de seleção confiáveis, além de realizar o tratamento dos dados e a utilização das informações. Para lidar com essas dificuldades, pode-se utilizar um tipo de pesquisa bibliográfica, também chamada de Revisão Sistemática, além das técnicas de Análise Bibliométrica. Esses mecanismos quantitativos de pesquisa contribuem para diminuir a subjetividade na escolha das publicações e viabilizar escolhas e tratamentos fidedignos de dados baseados em normas replicáveis e indicadores quantitativos (MEDEIROS; VIEIRA; BRAVIANO; GONÇALVES, 2015, p. 98).

A pesquisa por referências bibliográficas, parte fundamental do trabalho acadêmico, demanda rigor em termos de busca, seleção e tratamento de dados. Contribuem, neste processo, a revisão sistemática e a análise bibliométrica de literatura, com o propósito de integrar protocolos quantitativos e pesquisas de referências (MEDEIROS; VIEIRA; BRAVIANO; GONÇALVES, 2015, p. 93).

A pesquisa científica precisa se valer de suportes confiáveis em termos de referências. Revisão sistemática e análise bibliométrica figuram, nesse contexto, como uma necessidade, uma vez que fornece para o pesquisador uma matéria-prima criteriosamente selecionada. Justifica-se investir mais na disseminação de tais procedimentos de pesquisa em áreas em que ainda não são muito difundidas (MEDEIROS; VIEIRA; BRAVIANO; GONÇALVES, 2015, p. 107).

Quadro 1 - Exemplo de Checklist de revisão sistemática e análise bibliométrica.

\begin{tabular}{|l|l|}
\hline \multicolumn{1}{|c|}{ Sub-Etapa } & \multicolumn{1}{c|}{ Descrição } \\
\hline 1) Determine seus objetivos & $\begin{array}{l}\text { O que você deseja pesquisar? Qual o tema? Como } \\
\text { descrever seu objeto com palavras-chaves? }\end{array}$ \\
\hline $\begin{array}{l}\text { 2) Determine um descritor de } \\
\text { busca }\end{array}$ & $\begin{array}{l}\text { Teste os termos componentes do descritor um a } \\
\text { um no Google Scholar antes, para checar se são } \\
\text { pertinentes na busca. Depois dos termos, selecione } \\
\text { operadores lógicos para integrá-los, formando } \\
\text { assim o descritor. }\end{array}$ \\
\hline $\begin{array}{l}\text { 3) Escolha as bases de dados } \\
\text { pertinentes }\end{array}$ & $\begin{array}{l}\text { Selecione-as dentre aquelas disponíveis no Portal } \\
\text { de Periódicos }\end{array}$ \\
\hline
\end{tabular}




\begin{tabular}{|c|c|}
\hline Sub-Etapa & Descrição \\
\hline & da CAPES. \\
\hline $\begin{array}{l}\text { 4) Realize a busca usando o } \\
\text { descritor }\end{array}$ & $\begin{array}{l}\text { Em todas as bases de dados escolhidas na etapa } \\
\text { anterior. }\end{array}$ \\
\hline $\begin{array}{l}\text { 5) Filtre a busca por critérios } \\
\text { pré-selecionados }\end{array}$ & $\begin{array}{l}\text { Aplique filtros nas buscas feitas na Etapa } 4 \text {. } \\
\text { Exemplos de filtros: } \\
\text { a) apenas artigos em periódicos com peer review; } \\
\text { b) apenas publicações entre } 2004 \text { e } 2014 \text {; } \\
\text { c) apenas publicações disponíveis na base da } \\
\text { Capes. }\end{array}$ \\
\hline $\begin{array}{l}\text { 6) Use o EndNOTE (OBS: } 0 \\
\text { Zotero é uma Alternativa: } \\
\text { Software Livre para o EndNOTE) }\end{array}$ & $\begin{array}{l}\text { Pegue todos os artigos que restaram depois do } \\
\text { passo 5, faça download do arquivo .RIS deles (na } \\
\text { base de dados em que o achou). } \\
\text { Pegue esse arquivo .RIS contendo os dados de } \\
\text { todos os artigos, como por exemplo: autores, data } \\
\text { e local de publicação, resumo etc. } \\
\text { Abra no software EndNOTE, e selecione os artigos } \\
\text { por: } \\
\text { a) título; } \\
\text { b) palavras-chave; } \\
\text { c) resumo. }\end{array}$ \\
\hline 7) Sistematize a bibliografia & $\begin{array}{l}\text { Faça uma planilha mostrando os artigos que } \\
\text { sobraram depois } \\
\text { da etapa } 6 . \text { Nessa planilha, explicite o autor, ano de } \\
\text { publicação, título, fonte etc, de cada artigo. OBS: } \\
\text { Destaque itens da planilha } \\
\text { como "Temas mais frequentes", "Palavras-chaves } \\
\text { mais usadas", "Áreas" etc. }\end{array}$ \\
\hline $\begin{array}{l}\text { 8) Exponha os indicadores } \\
\text { bibliométricos de cada artigo } \\
\text { na planilha da etapa } 7\end{array}$ & $\begin{array}{l}\text { Selecione os indicadores bibliométricos mais } \\
\text { pertinentes para satisfazer os objetivos de sua } \\
\text { revisão (Etapa 1). }\end{array}$ \\
\hline 9) Monte gráficos para apresentar os resultados & $\begin{array}{l}\text { Crie tabelas e gráficos (histogramas, de pizza, } \\
\text { diagramas etc), para expressar os dados } \\
\text { bibliométricos dos artigos. Ex: principais autores, } \\
\text { conexões entre autores via citações, ranking de } \\
\text { publicações, regiões do mundo ou centros de } \\
\text { pesquisa mais importantes, timeline de } \\
\text { publicações etc. }\end{array}$ \\
\hline 10) Escreva um relatório & $\begin{array}{l}\text { Escreva um texto integrando dados da planilha } \\
\text { (Etapa 7) com os gráficos bibliométricos (Etapa 9), } \\
\text { com suas análises e interpretações. É esse texto, } \\
\text { com esses elementos todos, que } \\
\text { embasará sua pesquisa. }\end{array}$ \\
\hline
\end{tabular}

Fonte: Medeiros; Vieira; Braviano; Gonçalves, 2015, p. 102. 
Os artigos e periódicos foram selecionados utilizando a Base Sci Verse SCOPUS através das palavras chaves Fontes de Informação e Competitividade e Fontes de Informação e Inteligência Competitiva e os filtros aplicados foram a busca de revistas científicas com a Qualis A1, A2 e B1 no Portal de Periódicos da Capes. Os demais fatores não foram incluídos por serem considerados de baixo impacto. Os resultados obtidos foram exportados para uma planilha de Excel, formatados e importados para o software VosViewer com o intuito de esboçar a rede de conexão dos termos pesquisados.

Quadro 2 - Seleção das revistas científicas Qualis A1, A2 e B1.

\begin{tabular}{|c|c|c|c|}
\hline$\#$ & ISSN & Título da revista científica & Qualis \\
\hline 1 & $0022-0418$ & Perspectivas em Ciencia da Informacao & A1 \\
\hline 2 & $1518-8353$ & CIÊNCIA DA INFORMAÇÃO (ONLINE) & B1 \\
\hline 3 & $1562-4730$ & BIBLIOS (LIMA) & A1 \\
\hline 4 & $1099-1131$ & INTERNATIONAL JOURNALOF COMMUNICATION SYSTEMS & B1 \\
\hline 5 & $0034-7612$ & REVISTA DE ADMINISTRAÇÃO PÚBLICA (IMPRESSO) & B1 \\
\hline 6 & 2318-0889 & TRANSINFORMAÇÃO & A1 \\
\hline
\end{tabular}

Fonte: Elaborado pelas autoras a partir do Portal de Periódicos da Capes.

O Portal de Periódicos da Capes oferece textos completos disponíveis em mais de 38 mil publicações periódicas, internacionais e nacionais, e a diversas bases de dados que reúnem desde referências e resumos de trabalhos acadêmicos e científicos até normas técnicas, patentes, teses e dissertações dentre outros tipos de materiais, cobrindo todas as áreas do conhecimento.

Figura 1 - Aplicação da estratégia de seleção dos artigos e apresentação dos mapas de visualização das

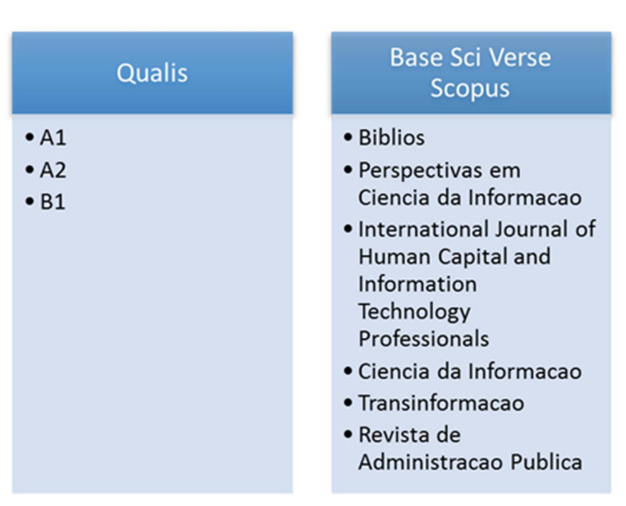
palavras-chave.

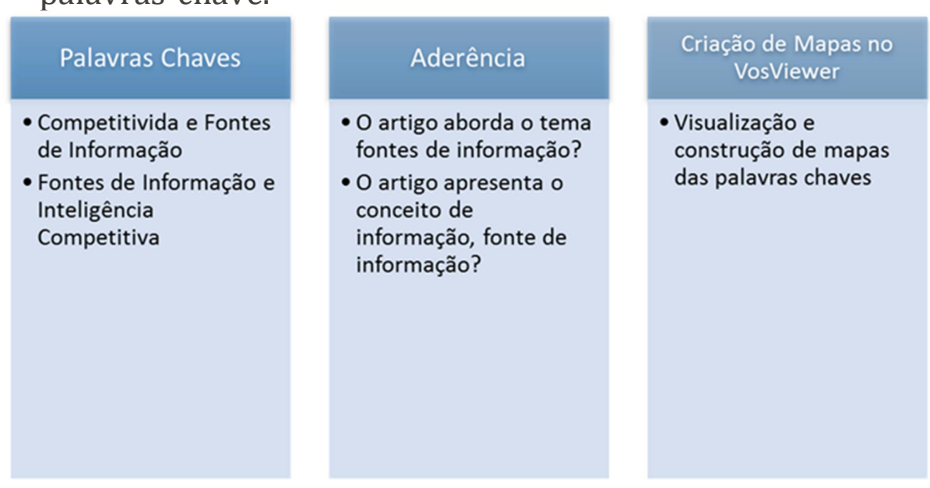

Fonte: Elaborada pelas autoras a partir da estratégia de análise adotada. 
A Editora Elsevier disponibiliza a base referencial Sci Verse SCOPUS pelo Portal de Periódicos da Capes por meio do contrato Elsevier B. V/Scopus. Tal base foi selecionada pelas autoras em função de ser composta por revistas nas áreas de conhecimento em questão e disponibilizar resumos, títulos e palavras chave e permite ainda a exportação no formato (.csv) adequado para utilização do algoritmo VosViewer.

Lima e Pereira (2018) dizem que o VOSViewer é uma ferramenta focada na visualização e construção de mapas bibliométricos. Com ele, mapas podem ser criados a partir de dados de rede, através dos algoritmos e de agrupamento VOS. O VOSViewer pode ser usado para explorar mapas sob diferentes perspectivas, cada uma enfatizando uma característica em específico como: co-ocorrência de citações, publicações, autores, mapas de palavras-chave, sendo esse último, a técnica utilizada neste artigo. Erik, Waltman (2010), Lima e Pereira (2018), ressaltam que o VOSViewer não é capaz de construir nenhum mapa de redes bibliométricas, apenas visualizá-lo.

Figura 2 - Detalhamento da estratégia de seleção dos artigos.

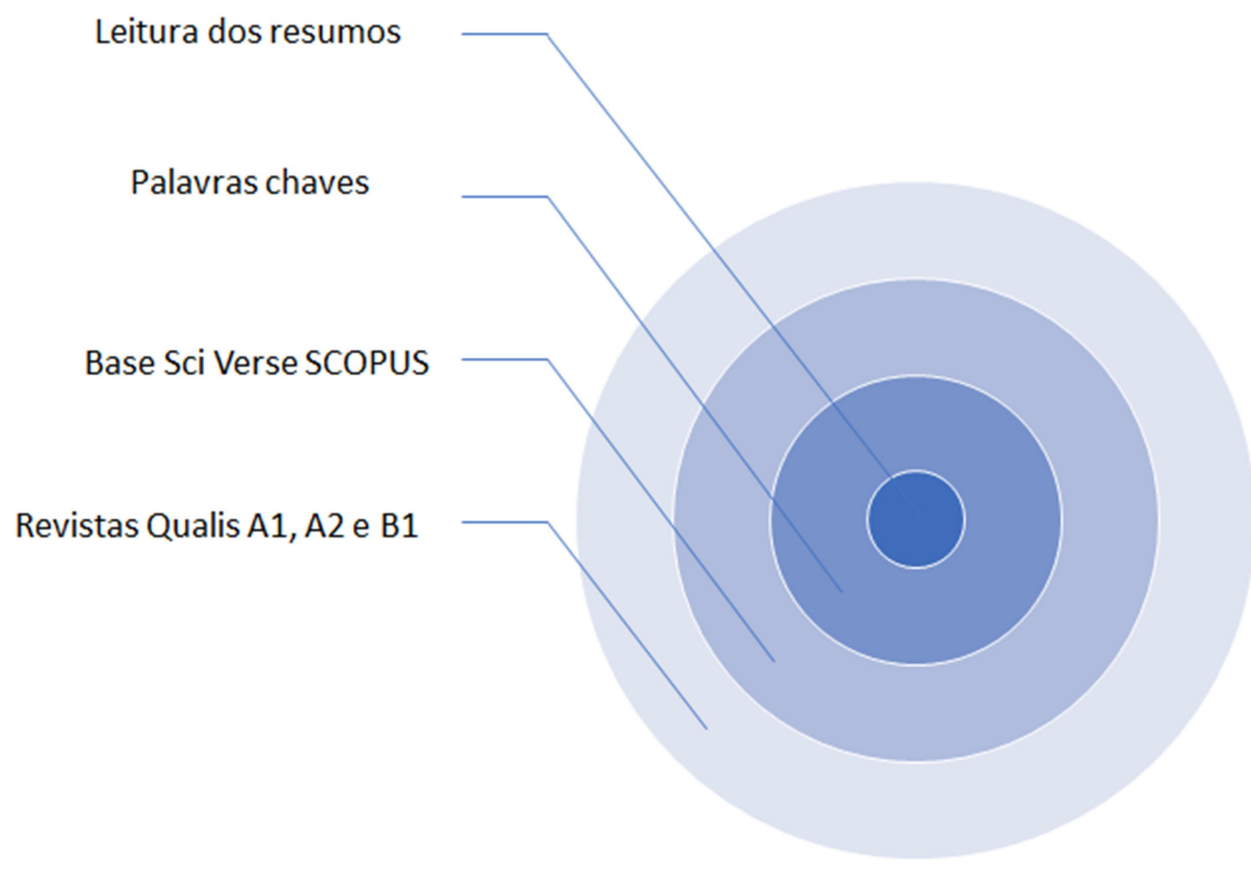

Fonte: Elaborado pelas autoras a partir de dados Base Sci Verse SCOPUS.

A pesquisa foi realizada com a utilização das palavras chave: inteligência competitiva, competitividade e fonte de informação, todas no resumo, nas palavras chave e no título dos artigos. 
No período de 2007 a 2018, a pesquisa retornou 345 artigos científicos dentro do tema proposto. Após o cruzamento das palavras chave na busca e a aplicação do critério com as classificações Qualis desejadas, A1, A2 e B1, o resultado foram 23 artigos.

Quadro 3 - Artigos científicos selecionados na Base Sci Verse SCOPUS com filtro Qualis A1, A2 e B1.

\begin{tabular}{|c|c|c|c|c|c|c|}
\hline & Autores & Título do periódico & Ano & Título da revista cientifica & Source & EID \\
\hline 1 & Inomata D.O., Araújo W.C.O. & Analysis of the Brazilian scientific production al & I 2015 & Biblios & $2-52.0-84936876178$ & Scopus \\
\hline 2 & Rodrigues C., Blattmann U. & Information management and the importance 0 & 2014 & Perspectivas em Ciencia da Informacao & $2-s 2.0-84908205942$ & Scopus \\
\hline 3 & V., Guimaräes L.O & Social networks, information, businesses genes & $=2010$ & Perspectivas em Ciencia da Informacao & $2-52.0-79251553512$ & Scopus \\
\hline 4 & Delaia C.R., Freire I.M. & Subsidies to a policy information management & 2010 & Perspectivas em Ciencia da Informacao & $2-52.0-79$ & Scopus \\
\hline 5 & Pinto S., Ferreira F. & Technological dissemination in the portuguese & 2010 & International Journal of Human Capital & 2-52.0-79960952097 & Scopus \\
\hline 6 & Araújo A.C., Bufrem L.S. & Information for business: Aspects of the nation & 2008 & Ciencia da Informacao & $2-52.0-70349830366$ & Scopus \\
\hline 7 & Assis W.M. & Sources of information for steel sector [Fontes c & c 2007 & $\mathrm{Cie}$ & $2-52.0$ & Scopus \\
\hline 8 & Da Silva MARQUES L.K., Vidi, & i. Prosumers and social networks as marketing in & 2018 & Iformacao & $2-s 2$ & Scopus \\
\hline 9 & Araújo W.C.O., da Sil & Flow information in innovation projects: Study it & I 2017 & Perspectivas em Ciencia da Informacao & $2-52.0-85$ & Scopus \\
\hline 10 & Costa H., Matias M. & (National Institutes of Science and Technology it & 2017 & Biblios & $2-52.0-8$ & Scopus \\
\hline 11 & Hoffmann W. & Knowledge management and information mana & 2016 & 5 Cier & $2-52.0$ & Scopus \\
\hline 12 & Perei & , relev: & 2016 & $5 \mathrm{Pe}$ & $2-5$ & Scopus \\
\hline 13 & , Sade W. & Competitive intelligence in the contex & 2016 & 5 Pers & $2-52$ & Scopus \\
\hline 14 & Silva J.F. & Information unit: Case study of the euvaldo lodi & 2016 & Ciencia da Informacao & 2-s2. & Scopus \\
\hline 15 & Da Silva B.G.M., Da Silva M. & Analysis of scientific production in information & 2015 & Biblios & $2-52.0$ & Scopus \\
\hline 16 & Rodrigues & Information management & 2014 & Perspectivas em Ciencia da & $2-52.0$ & Scopus \\
\hline 17 & Rezende & o Strategic alignment drivers: $P$ & i 2013 & Revista de Administracao Publica & $2-52.0$ & Scopus \\
\hline 18 & Feitos & ational interp & 2011 & Ciencia da Informacao & $2-52.0-8$ & Scopus \\
\hline 19 & de Oliveira P.H., Gonçalves & Mapping and measuring the degree of internal & 2011 & Perspectivas em Ciencia da Informacao & $2-52.0-80054120449$ & Scopus \\
\hline 20 & de Lorenzi Cancellier E.L.P., & Differences in the information activity monitoril & 2011 & 1. Perspectivas em Ciencia da Informacao & $2-52.0-80054102829$ & Scopus \\
\hline 21 & Brum M.A.C., Barbos R.R. & Search and use information behavior: A study w & 2009 & Perspectivas em Ciencia da Informacao & $2-52.0-70549114769$ & Scopus \\
\hline 22 & de Oliveira P.H. & Proposal of a methodology to measure the evel & 2009 & Perspectivas em Ciencia da Informacao & $2-52.0-70349337132$ & Scopus \\
\hline 23 & Pereira F.C.M., Barbosa R.R. & The use of information sources by business con & 2008 & 3 Perspectivas em Ciencia da Informacao & $2-52.0-45349103476$ & Scopus \\
\hline
\end{tabular}

Fonte: Elaborado pelas autoras a partir de dados Base Sci Verse SCOPUS.

Depois de investigadas as recorrências das palavras chaves nos periódicos da base Sci Verse SCOPUS foram selecionados seis (6) artigos científicos em duas (2) revistas mais relevantes ao tema.

\section{RESULTADO E DISCUSSÃO}

\subsection{Análise dos resultados da base sci verse scopus}

Demonstrando a recorrência do tema proposto, verifica-se na dispersão da figura 3, os 23 artigos publicados no período de 2007-2018 com as palavras-chave, fontes de informação e inteligência competitiva e fontes de informação e competitividade em revistas brasileiras de alto impacto, ou seja, Qualis A1, A2 e B1 com ao menos uma publicação por ano. 
Figura 3 - Publicações com as palavras-chave fontes de informação e inteligência competitiva e fontes de informação e competitividade por ano.

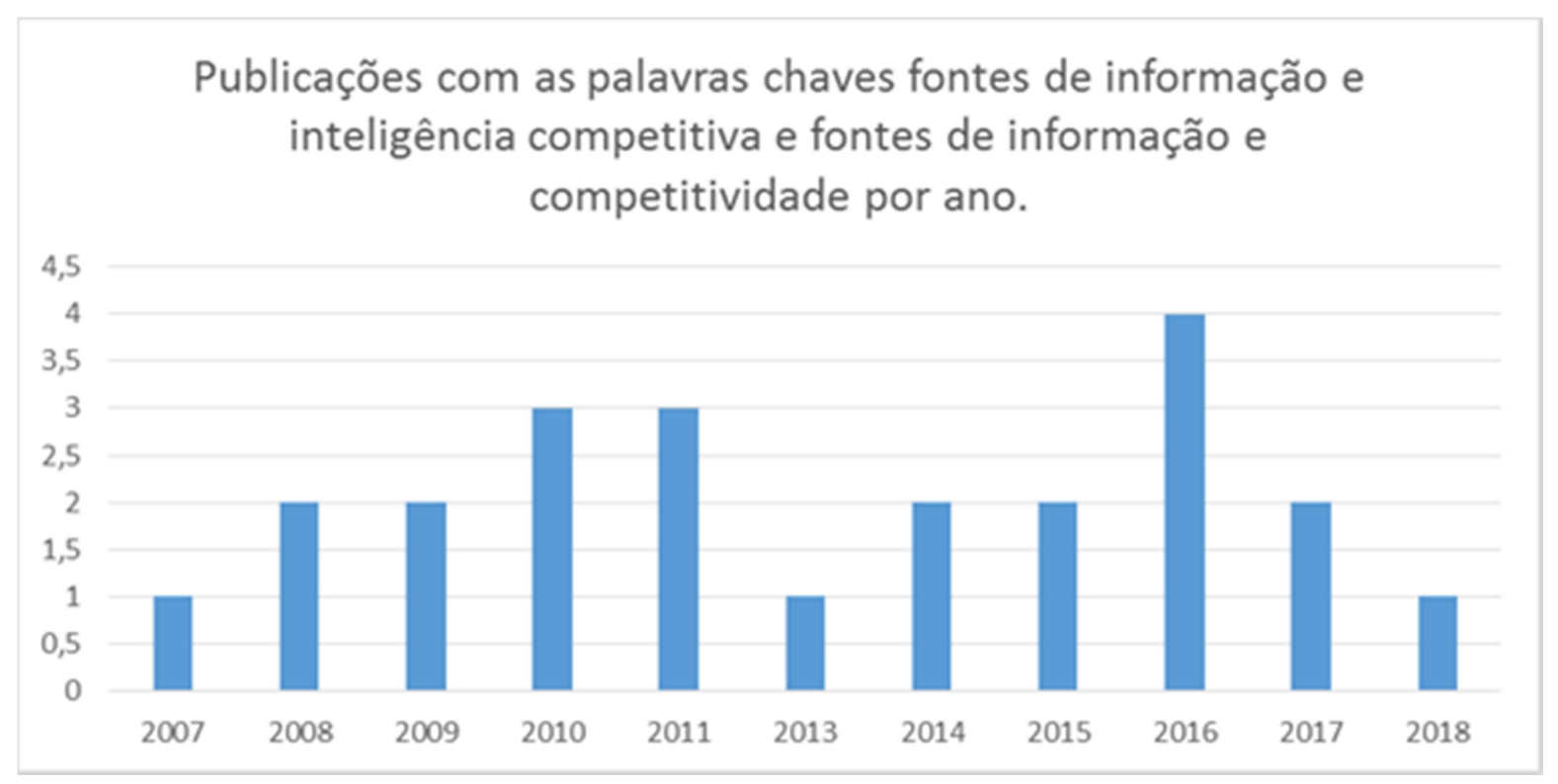

Fonte: Elaborado pelas autoras a partir de dados Base Sci Verse SCOPUS.

As revistas científicas Perspectivas em Ciência da Informação e Ciência da Informação juntas publicaram 74\% dos artigos sobre o tema proposto.

Os artigos selecionados pelas autoras para dar maior embasamento teórico ao estudo foram extraídos dessas revistas.

Figura 4 - Títulos das revistas científicas por quantidade de publicações do tema nos últimos 10 anos.

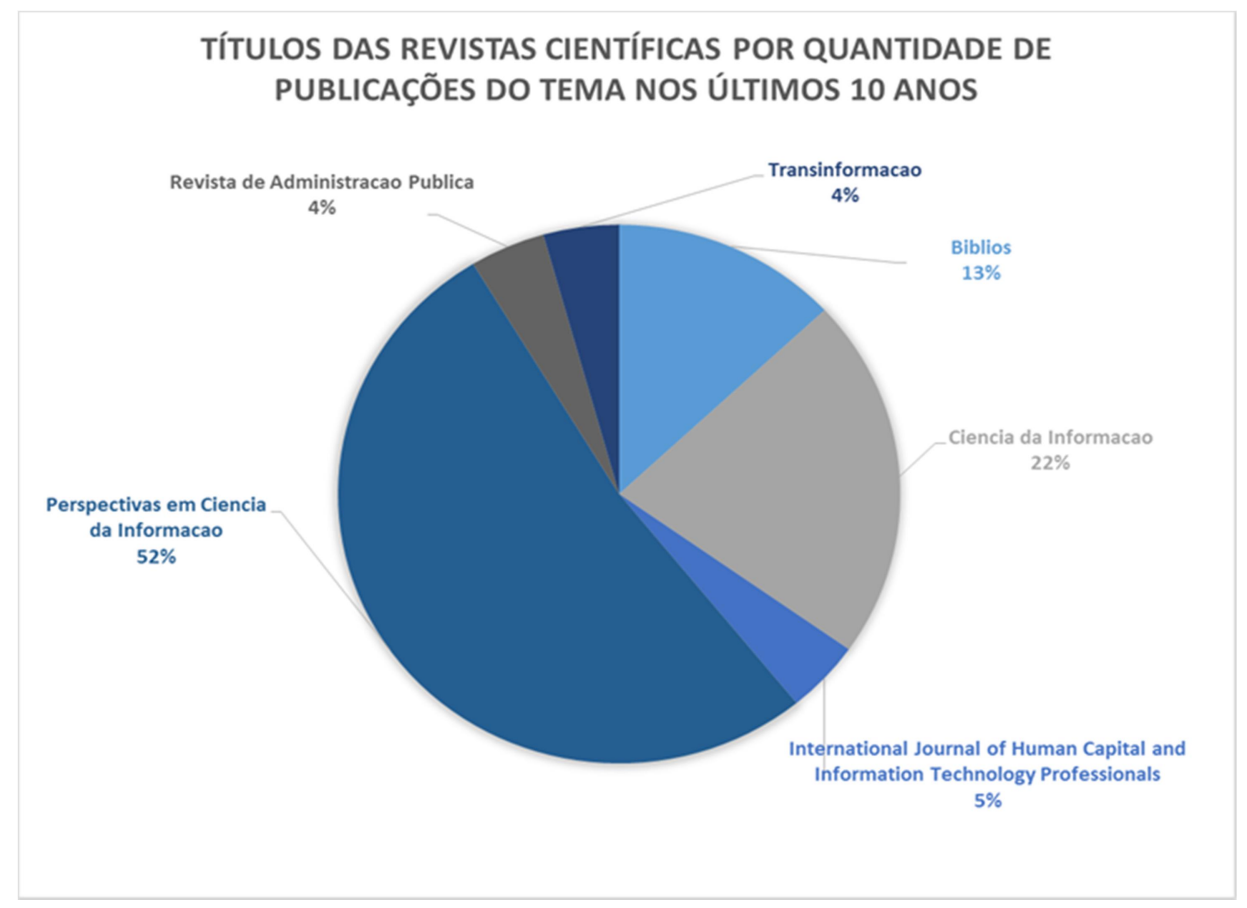

Fonte: Elaborado pelas autoras a partir de dados Base Sci Verse SCOPUS. 


\subsection{Análise resultados do VOSviewer}

Os termos mais utilizados nos artigos pré-selecionados através das palavraschave inteligência competitiva, competitividade e fonte de informação na Base scopus foram: company, competitive intelligence, minas gerais, organization, social network, state, frequency, methodology, relevance, source, study, analysis, article, scientific production, technological publication, information management, knowledge, use, information, organizational interpretation.

O critério de inclusão das palavras como a repetição mínima de cinco vezes nos artigos selecionados.

Quadro 4 - Filtro dos principais termos incidentes nos artigos selecionados.

\begin{tabular}{|c|c|c|c|c|c|c|c|c|c|c|}
\hline$\#$ & Termos & $\mathbf{x}$ & $\mathbf{y}$ & Grupos & $\begin{array}{l}\text { Peso } \\
\text { <links> }\end{array}$ & $\begin{array}{l}\text { Peso \&orça } \\
\text { Total links> }\end{array}$ & $\begin{array}{c}\text { Peso } \\
\text { <Ocorrências> }\end{array}$ & $\begin{array}{c}\text { Ano } \\
\text { Publicação }\end{array}$ & $\begin{array}{l}\text { Média de } \\
\text { Citações }\end{array}$ & $\begin{array}{c}\text { Nota< Média norm. } \\
\text { Citações }\end{array}$ \\
\hline 3 & company & -0.3765 & -0.4757 & 1 & 14 & 160 & 14 & 2014 & 0.3571 & 11.786 \\
\hline 4 & competitive intelligence & -0.6984 & -0.4421 & 1 & 10 & 65 & 5 & 2016 & 0 & 1 \\
\hline 10 & minas gerais & -0.2903 & -0.1509 & 1 & 11 & 40 & 6 & 2015 & 0.1667 & 10.833 \\
\hline 11 & organization & -0.6862 & 0.1781 & 1 & 13 & 96 & 11 & 2014 & 0 & 0.9091 \\
\hline 15 & social network & -0.6675 & -0.7861 & 1 & 6 & 100 & 5 & 2018 & 0 & 1 \\
\hline 17 & state & -0.564 & -0.0891 & 1 & 8 & 42 & 5 & 2013 & 0 & 1 \\
\hline 5 & frequency & 0.2252 & -0.4053 & 2 & 11 & 50 & 5 & 2011 & 2.4 & 12.667 \\
\hline 9 & methodology & 0.5433 & 0.5064 & 2 & 11 & 64 & 5 & 2011 & 1 & 0.8 \\
\hline 13 & relevance & -0.1309 & -0.287 & 2 & 11 & 53 & 5 & 2011 & 2.2 & 11.667 \\
\hline 16 & source & 0.1383 & -0.0296 & 2 & 14 & 365 & 31 & 2012 & 1.871 & 10.376 \\
\hline 18 & study & 0.0514 & 0.036 & 2 & 19 & 269 & 20 & 2014 & 0.95 & 10.417 \\
\hline 1 & analysis & 0.4968 & -0.2614 & 3 & 15 & 145 & 11 & 2015 & 0.3636 & 10.909 \\
\hline 2 & article & 0.9803 & -0.0629 & 3 & 14 & 59 & 7 & 2014 & 0.2857 & 10.238 \\
\hline 14 & scientific production & 12.694 & -0.0932 & 3 & 5 & 36 & 5 & 2015 & 0 & 1 \\
\hline 19 & technological publication & 12.943 & -0.0503 & 3 & 4 & 30 & 5 & 2017 & 0 & 1 \\
\hline 7 & information management & -0.1514 & 0.7686 & 4 & 9 & 95 & 5 & 2014 & 1.2 & 1 \\
\hline 8 & knowledge & -0.2177 & 0.4849 & 4 & 14 & 110 & 8 & 2014 & 1.5 & 1 \\
\hline 20 & use & 0.5031 & 0.3656 & 4 & 15 & 169 & 11 & 2013 & 24.545 & 10.455 \\
\hline 6 & information & -0.4804 & 0.2547 & 5 & 17 & 405 & 31 & 2014 & 0.9032 & 0.8978 \\
\hline 12 & organizational interpretation & -12.387 & 0.5395 & 5 & 3 & 25 & 5 & 2011 & 0 & 0 \\
\hline
\end{tabular}

Fonte: Elaborado pelas autoras a partir do VOSViewer.

Os temos que obtiveram a maior frequência, conforme a figura 5, foram information e source. 0 modismo dessas palavras nos artigos reflete, a qualidade, a clareza e a tangibilidade da pesquisa, que a partir das revistas classificadas como Qualis A1, A2 e B1 e da seleção do tema proposto na Base Sci Verse SCOPUS através das palavras-chave retornaram os arquivos apropriados ao tema naquela base. 
Figura 5 - Frequência de termos agrupados no VOSViewer.

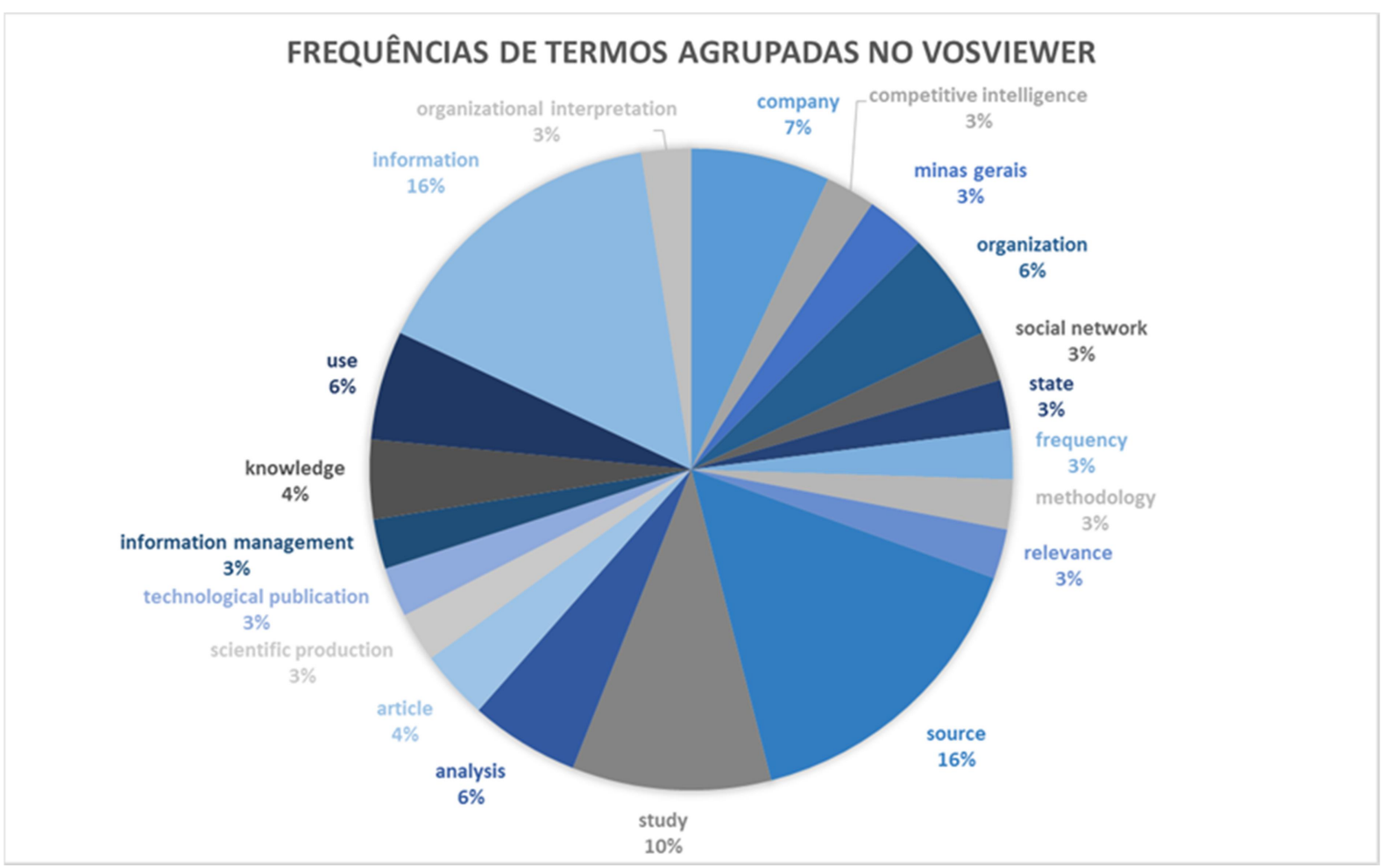

Fonte: Elaborado pelas autoras a partir do VOSViewer.

O software VOSviewer mostra as palavras que são mais relevantes na pesquisa e os termos podem ser agrupados formando os chamados clusters que definem as cores dos círculos e das linhas de ligação dos termos.

A figura 6 (a seguir) apresenta o mapa com todos os termos selecionados pelo software, 20 termos que são apresentados em cinco grupos de imagens (cores diferentes), que representam os relacionamentos entre as palavras e a frequência de citações referentes às mesmas.

Quanto às relações, temos na parte inferior da imagem e também na parte superior da figura 6, palavras irrelevantes, citadas com menor frequência, que revelam mínimas relações existentes entre os termos, apresentadas por círculos menores pelo software.

Na parte central da figura 6, estão em evidência palavras com maior número de citações e maior densidade de relações, representadas por círculos maiores. 
68 | Ferreira; Jardim; Ziviani | Fontes de informação

Figura 6 - Agrupamento de termos 2007-2018.

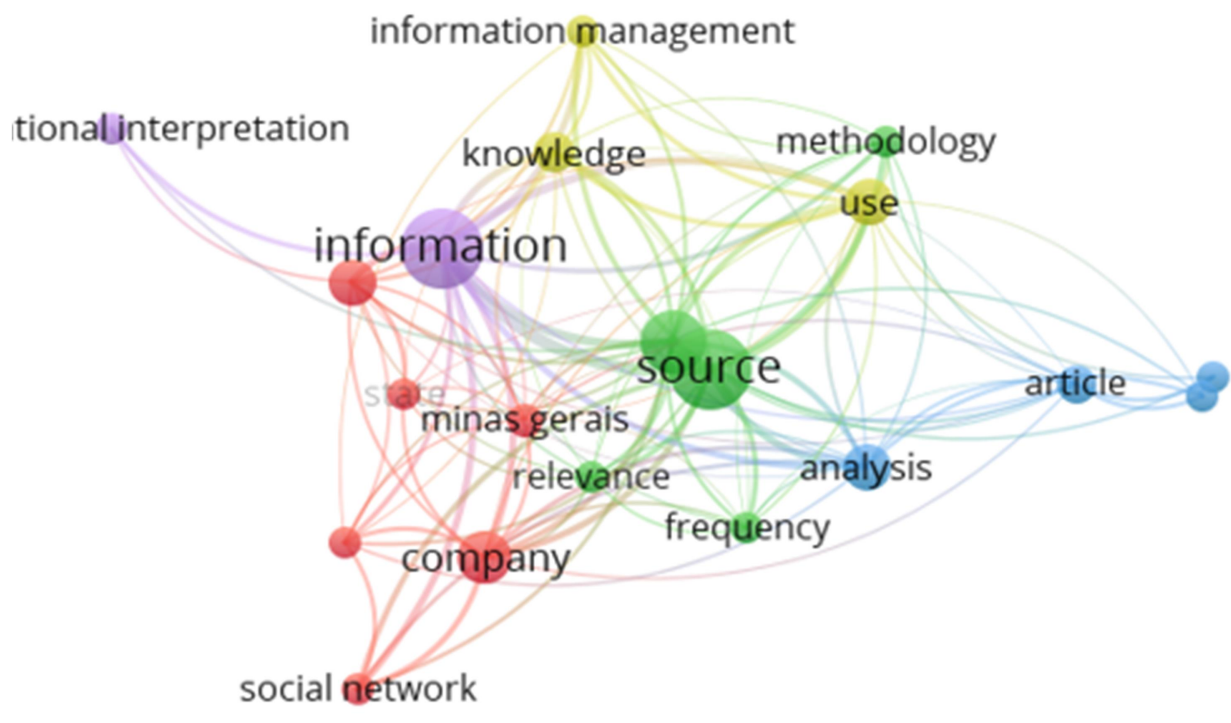

Fonte: Elaborado pelas autoras a partir da Base Sci Verse SCOPUS no software VOSViewer.

Na figura 7, o enfoque é conferido ao relacionamento de uma das palavras chave, o termo Intelligence Competitive. Verifica-se que o termo, apesar de estar em um clusters distinto (cores diferentes), se relaciona com outra palavra chave determinante da pesquisa, fonte de informação.

Figura 7 - Agrupamento de termos destaque o grupo Inteligência Competitiva.

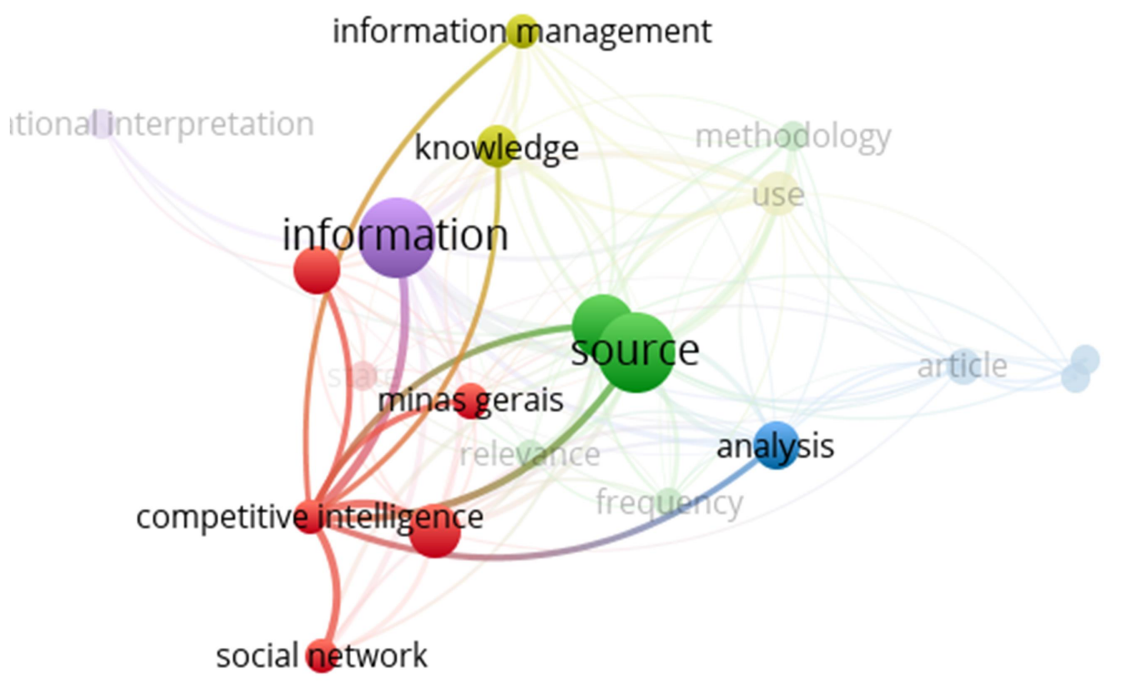

Fonte: Elaborado pelas autoras a partir da Base Sci Verse SCOPUS no software VOSViewer. 
Na figura 8, o enfoque é conferido ao relacionamento de uma das palavras chaves, o termo source. Verifica-se que existe um forte relacionamento da palavra source com os termos information, knowledge, study, analysis, use, company e information management.

Figura 8 - Clusterização de termos destaque o grupo Fonte no período 2007-2018.

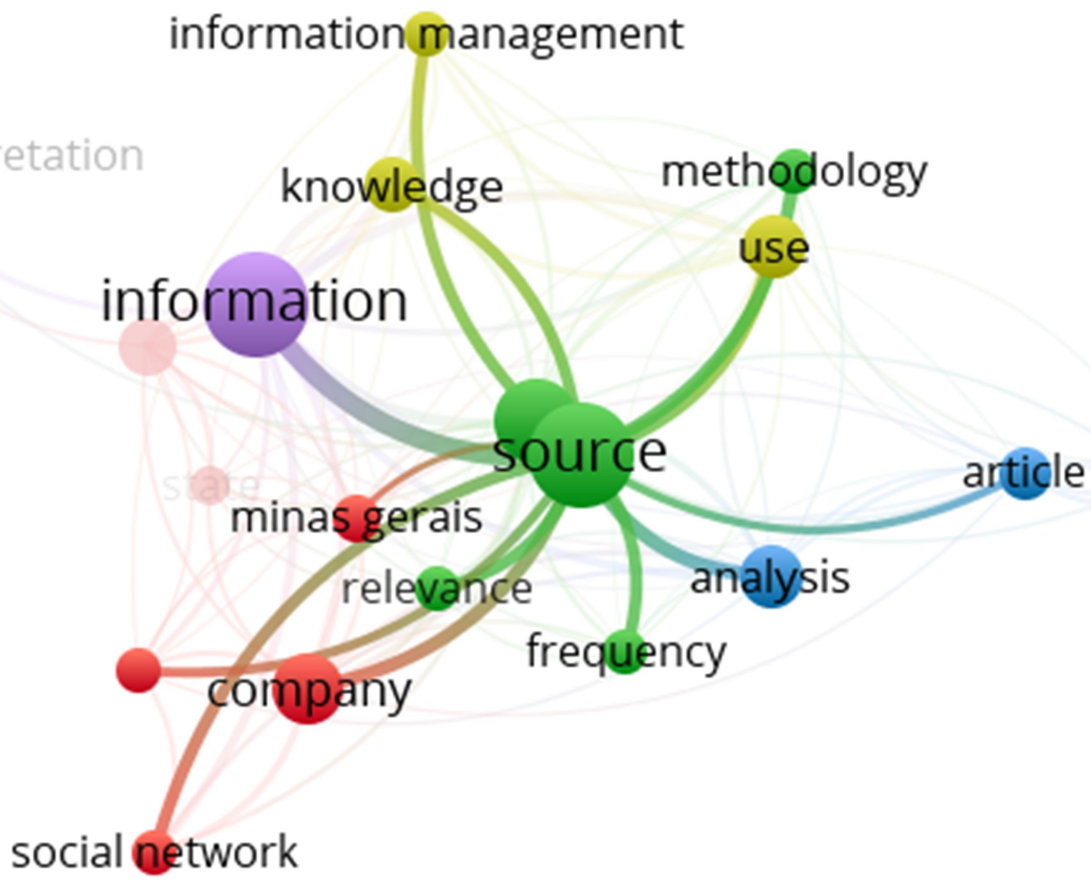

Fonte: Elaborado pelas autoras a partir da Base Sci Verse SCOPUS no software VOSViewer.

Os gráficos elaborados a partir dos dados importados no software VosViewer e o estudo dos artigos pertinentes ao tema apontam uma relação direta entre a importância da informação dentro das organizações e as principais fontes utilizadas para o levantamento dessas informações. Constatamos isso principalmente nos textos desse estudo que abordam o novo paradigma organizacional, a evolução da era da informação e do conhecimento e as principais fontes utilizadas pelas empresas contrapondo o gráfico da figura 5 e a clusterização dos termos Source e Information na Figura 8.

Ainda em relação a esses termos apresentados é possível verificar na literatura sobre a quantidade de informação produzida continuamente por organizações e indivíduos e a obtenção dessas informações para que as mesmas produzam significados satisfatórios, as chamadas fontes de informação. 
A junção dos termos fontes de informação e inteligência competitiva é apresentada por Rodrigues e Blattmann (2014) ao abordarem sobre o gerenciamento de organizações orientadas ao conhecimento como recursos para aumento de eficiência e geração de vantagem competitiva.

Os autores também apresentam vasta literatura sobre a informação e o conhecimento como geradores de qualidade e eficiência nos processos organizacionais. Entendimento esse apresentado com maior clareza na figura 7 que apresenta um agrupamento de termos em destaque ao grupo Inteligência Competitiva.

As fontes de informação são analisadas e classificadas segundo a visão e opinião dos principais autores mencionados.

Para finalizar o estudo, a obtenção e o uso da informação e suas fontes são citados como fatores de transformações sociais e econômicas. Defende-se a importância de integrar a gestão da informação e do conhecimento em ambientes organizacionais.

\section{CONSIDERAÇÕES FINAIS}

O estudo identificou que a produção científica distribuída entre os anos de 2007 a 2018 é composta por artigos que abordam temas variados dentro da perspectiva da gestão da informação relacionados às palavras-chave: inteligência competitiva, competitividade e fontes de informação.

Segundo o software de mineração de dados, as revistas científicas Perspectivas em Ciência da Informação e Ciência da Informação foram responsáveis por 74\% dos artigos publicados sobre o tema proposto. As palavras-chave (inteligência competitiva, competitividade, fonte de informação e gestão do conhecimento) usadas como estratégia de busca na base Scopus se mostraram eficientes e precisas na recuperação de trabalhos publicados a nível nacional e internacional, que contemplam os aspectos da gestão da informação e fontes de informação.

Novas etapas podem ser seguidas a partir deste estudo preliminar, como pesquisa por autores e instituições, a fim de mapear redes de colaboração, aprofundar as análises e desvelar características desta importante área do conhecimento, na finalidade de que se possa criar grupos de estudos para interação.

Os autores analisados apontaram a necessidade do mapeamento das fontes de informação para a geração de indicadores, que poderão ser utilizados pelas 
organizações em estratégias de aumento da competitividade e eficácia na tomada de decisões.

As informações obtidas através de fontes confiáveis de dados podem ser utilizadas, dentre outras, em demandas organizacionais, que vão desde o monitoramento da concorrência, análise do contexto mercadológico para inovação ou lançamento de novos produtos e apoio à diretoria para uma mudança no posicionamento estratégico.

Num contexto de alteração constante das dinâmicas de mercado, as organizações podem utilizar as fontes de informação como ferramentas para a geração de conhecimentos que auxiliarão, de maneira mais assertiva, na tomada de decisão rumo à construção da diferenciação competitiva.

Os artigos examinados na amostra demonstram que as pesquisas sobre informação, fonte de informação e inteligência competitiva convergem para o paradigma econômico e tecnológico e que as fontes de informação são ferramentas importantes para que a gestão da informação possa emergir como mecanismo estratégico essencial ao desempenho empresarial.

\section{REFERÊNCIAS}

ASSIS, Wilson Martins. Fontes de informação para o setor siderúrgico. Ciência da

Informação, Brasília, v. 36, n. 2, p. 92-105, set. 2008. Disponível em: http://revista.ibict.br/ciinf/article/view/11 80. Acesso em: 1o maio 2018.

BRUM, Marco Antônio Carvalho; BARBOSA, Ricardo Rodrigues. Comportamento de busca e uso da informação: um estudo com alunos participantes de empresas juniores.

Perspectivas em Ciência da Informação, Belo Horizonte, v. 14, n. 2, p. 52-75, maio/ago. 2009. Disponível em: http://www.scielo.br/pdf/pci/v14n2/v14n2 a05.pdf. Acesso em: 27 abr. 2018.

FEITOSA, Maria José Silva; CALDAS, Patrícia Trindade; CÂNDIDO, Gesinaldo Ataíde. A interpretação organizacional em empresas de tecnologia da informação e comunicação (TIC): um estudo na Incubadora Tecnológica de Campina Grande-PB. Ciência da

Informação, Brasília, v. 40 n. 2, p 192-206, maio/ago. 2011. Disponível em: revista.ibict.br/ciinf/article/view/1310. Acesso em: 27 abr. 2018.

LIMA RUAS, Terry; PEREIRA, Luciana. Como construir indicadores de Ciência, Tecnologia e Inovação utilizando Web of Science, Derwent World Patent Index, Bibexcel e Pajek? Perspectivas em Ciência da Informação, Belo Horizonte, v. 19, n. 3, p. 52-81, set. 2014. Disponível em: http://portaldeperiodicos.eci.ufmg.br/index. php/pci/article/view/1678. Acesso em: 03 maio 2018.

MARQUES, Lidiany Kelly da Silva; VIDIGAL, Frederico. Prosumers e redes sociais como fontes de informação mercadológica: uma análise sob a perspectiva da inteligência competitiva em empresas brasileiras. 
TransInformação, Campinas, v. 30, n. 1, p. 1-14, jan./abr. 2018. DOI: http://dx.doi.org/10.1590/231808892018000100001 . Acesso em: 29 set. 2018.

OLIVEIRA, Paulo Henrique; SADE, Wagner. Inteligência competitiva no contexto das empresas mineiras de artefatos de estanho. Perspectivas em Ciência da Informação, Belo Horizonte, v. 21, n. 1, p. 23-41, jan./mar. 2016. Disponível em: http://portaldeperiodicos.eci.ufmg.br/index. $\mathrm{php} / \mathrm{pci} /$ article/view/1885. Acesso em: 30 set. 2018.

PEREIRA, Frederico César Mafra. Fontes de informação para negócios: análise sobre frequência, relevância e confiabilidade, baseada em estudo empírico com empresários e gestores organizacionais. Perspectivas em Ciência da Informação, Belo Horizonte, v. 21, n. 2, p. 100-119, abr./jun. 2016. Disponível em: http://portaldeperiodicos.eci.ufmg.br/index. php/pci/article/view/2502. Acesso em: 27 abr. 2018.

PEREIRA, Frederico César Mafra; BARBOSA, Ricardo Rodrigues. Uso de fontes de informação por consultores empresariais: um estudo junto ao mercado de consultoria de Belo Horizonte. Perspectivas em Ciência da Informação, Belo Horizonte, v. 13, n. 1, p. 95-111, jan./abr. 2007. Disponível em: http://portaldeperiodicos.eci.ufmg.br/index. php/pci/article/view/163. Acesso em: 27 abr. 2018.

RODRIGUES, Charles; BLATTMANN, Ursula. Gestão da informação e a importância do uso de fontes de informação para geração de conhecimento. Perspectivas em Ciência da Informação, Belo Horizonte, v. 19, n. 3, p. 429, set. 2014. Disponível em:

http://portaldeperiodicos.eci.ufmg.br/index. $\mathrm{php} / \mathrm{pci} / \mathrm{article} / \mathrm{view} / 1515$. Acesso em: $1^{\mathrm{o}}$ maio 2018. 